\title{
Dry Eye Symptoms Are Increased in Mice Deficient in Phospholipid Transfer Protein (PLTP)
}

\author{
Niko L. Setälä, ${ }^{, \dagger \ddagger}$ Jari Metso, ${ }^{\ddagger}$ Matti Jauhiainen, ${ }^{\ddagger}$ \\ Antti Sajantila, ${ }^{\S}$ and Juha M. Holopainen* \\ From the Departments of Ophthalmology, ${ }^{*}$ and Forensic \\ Medicine, ${ }^{\Im}$ University of Helsinki, Helsinki; the Department of \\ Ophthalmology, University of Turku; and the National Institute \\ for Health and Welfare and Institute for Molecular Medicine, ${ }^{\neq}$ \\ Biomedicum, Helsinki, Finland
}

In the tear fluid the outermost part facing the tear-air interface is composed of lipids preventing evaporation of the tears. Phospholipid transfer protein (PLTP) mediates phospholipid transfer processes between serum lipoproteins and is also a normal component of human tears. To study whether PLTP plays any functional role in tear fluid we investigated PLTPdeficient mice, applying functional and morphologic analyses under normal housing and experimentally induced dry eye conditions. Aqueous tear fluid production, corneal epithelial morphology, barrier function, and occludin expression were assessed. In mice with a full deficiency of functional PLTP enhanced corneal epithelial damage, increased corneal permeability to carboxyfluorescein, and decreased corneal epithelial occludin expression were shown. These pathologic signs were worsened by experimentally induced dry eye both in wild-type and PLTP knock-out mice. Deficiency in the production of tear PLTP in mice is accompanied by corneal epithelial damage, a feature that is typical in human dry eye syndrome (DES). To complement animal experiments we collected tear fluid from human dry eye patients as well as healthy control subjects. Increased tear fluid PLTP activity was observed among DES patients. In conclusion, the presence of PLTP in tear fluid appears to be essential for maintaining a healthy and functional ocular surface. Increased PLTP activity in human tear fluid in DES patients suggests an ocular surface protective role for this lipid transfer protein. (Am J Pathol 2011, 178:2058-2065; DOI: 10.1016/j.ajpath.2011.01.027)

Dry eye syndrome (DES) is a multifactorial disease of the ocular surface. DES is accompanied by tear film instability, ${ }^{1}$ increased osmolarity, ${ }^{2,3}$ inflammation of the ocular surface, ${ }^{4}$ and abnormalities in tear fluid components, especially lipids. ${ }^{5}$ Together these may lead to ocular sur- face damage. ${ }^{6}$ The conventional structure of the tear film consists of three layers: a superficial lipid layer, an aqueous middle layer, and a precorneal mucin layer. ${ }^{7,8}$ It appears, however, that the two latter compartments form a somewhat homogenous gel-like and mucin-enriched fluid. 9,10 The superficial lipid layer is a complex mixture of polar and nonpolar lipids arranged into a layered structure. Based on the hydrophobic effect it has been suggested that the polar phospholipids are aligned adjacent to the aqueous-mucin layer and externally to this a layer composed of nonpolar lipids, such as cholesteryl esters and triglycerides, face the tear-air interface..$^{8,11,12}$ The chemical composition and comprehensive lipid analysis of tear fluid have yet to be revealed. It is, however, clear that an imbalance of lipid layer in the tear fluid is involved intimately in the pathogenesis of DES.

Similarly to cellular membranes ${ }^{13}$ the tear fluid lipid layer is by no means a static lipid membrane. A diminished amount of certain lipids increases the evaporation rate and excess lipids cause thickening and packing difficulties in the air-tear interface leading to formation of lipid aggregates in the tear fluid. Because of the properties of lipids it is quite likely that lipid aggregates may contaminate the mucins as well as even corneal epithelial cells, rendering these to become less wettable. Accordingly, an active protein-mediated transport mechanism is needed. Glasgow and collaborators ${ }^{14}$ previously showed that tear fluid lipocalin is able to bind lipids in the tear fluid and prevent contamination of the ocular surface. Yet, we previously showed that lipocalin does not actually possess lipid transport activity and that other such proteins are actually found in the tear fluid. ${ }^{15,16}$

We earlier showed that high-active form of phospholipid transfer protein (PLTP), a glycoprotein with phospholipid transfer activity, is secreted mainly from the lacrimal gland ${ }^{17}$ and is a normal component of the human tear fluid. ${ }^{16}$ In plasma PLTP transfers different phospho-

Supported by the Finnish Eye Foundation (N.L.S., J.M.H.), The Finnish Eye and Tissue Bank Foundation (N.L.S., J.M.H.), the Finnish Foundation for Cardiovascular Research (M.J.), the Academy of Finland (J.M.H.), and the Sigrid Juselius Foundation (M.J., J.M.H.).

Accepted for publication January 18, 2011

Address reprint requests to Juha Holopainen, M.D., Helsinki Eye Lab, Department of Ophthalmology, University of Helsinki, Haartmaninkatu 4 C, 00290 Helsinki, Finland. E-mail: juha.holopainen@hus.fi. 
lipid species, but not neutral lipids, between lipoprotein particles, ${ }^{18}$ and has an important role in high-density lipoprotein metabolism. ${ }^{19}$ The human lung tissue, where PLTP is found at an air-water environment (ie, similar to the tear fluid), displays high levels of PLTP compared with other tissues. PLTP is highly expressed in alveolar type II cells, and, notably, is induced during hypoxia and in emphysema, ${ }^{20}$ suggesting novel surface protective properties of this molecule. Recently, we elucidated the mechanism of PLTP-facilitated phospholipid transfer ${ }^{21}$ and very recently showed that PLTP interacts with human tear fluid mucins. ${ }^{17}$ These findings together suggest that PLTP may play a role in the tear film lipid homeostasis by preventing ocular surface damage and maintaining the anterior lipid layer. Disturbances in the secretion of functional PLTP may affect the stability and/or function of the tear fluid anterior lipid layer.

Here, we show by using a PLTP knock-out (KO) mouse model that in mouse tear fluid the absence of PLTP leads to similar corneal morphologic changes that typically are seen in DES. Human subjects suffering from DES show increased levels of PLTP activity. Our data suggest that at least in mice PLTP is part of the machinery that is important for maintaining the delicate homeostasis between corneal epithelial cells and normal tear fluid and in part in the prevention of DES.

\section{Material and Methods}

\section{Materials}

Transdermal scopolamine patches were obtained from Novartis (Scopoderm; Novartis International AG, Basel, Switzerland). Carboxyfluorescein (CF) $0.3 \%$ was from Holles Laboratories (Cohasset, MA). Schirmer paper was purchased form Zabby's (New Delhi, India). Polyclonal rabbit anti-occludin was from Zymed (San Francisco, CA). mAb59 IgG and rabbit polyclonal (R290 lgG) antibodies against human PLTP were produced as described earlier. ${ }^{22}$ Secondary antibodies, goat anti-mouse IgG horseradish peroxidase conjugate and goat antirabbit IgG horseradish peroxidase conjugate were purchased from Bio-Rad Laboratories (Hercules, CA). Alexa 488-conjugated goat anti-rabbit immunoglobulin was purchased from Molecular Probes (Eugene, OR). All other chemicals were obtained from Sigma-Aldrich (St. Louis, MO).

\section{Animals}

C57BL/6 wild-type (WT) mice (Charles River, Wilmington, MA) and C57BL/6 PLTP KO mice ${ }^{23}$ were bred in Taconic Europe Facilities (Ejby, Denmark) and then transferred to the National Public Health Institute (Helsinki, Finland) Animal Care Centre for further breeding. The mice were housed in a room under a controlled temperature $\left(23^{\circ} \mathrm{C} \pm\right.$ $1^{\circ} \mathrm{C}$ ) and light cycle, with free access to water and standard mouse chow (no. 2018, 18\% protein, 5\% fat; Harlan Teklad Global Diets, Blackthorn, UK). All of the animal experiments were conducted under the National Public Health Institute guidelines (license KTL 2004-02) for the humane treatment of laboratory animals. All procedures in the study protocol adhered to the Association for Research in Vision and Ophthalmology Statement for the Use of Animals in Ophthalmic and Vision Research.

\section{Human Subjects}

This part of the study was performed according to the principles of the Declaration of Helsinki, and was approved by the Ethics Committee of the Hospital District of Southwest Finland. Informed consent was obtained from each subject. Tear fluid was collected from dry eye patients ( $n=7$; age, 28-66 years; 2 men and 5 women) and healthy subjects ( $n=4$; age, 32-38 years; 2 men and 2 women). Except for typical dry eye symptoms and findings, the clinical investigation of the subjects before collection of tear fluid showed no signs of ocular inflammation or allergy.

\section{Methods}

\section{Blood Samples}

Blood samples were collected from vena saphena magna into sterile heparin-containing tubes. The samples were kept at room temperature for 1 hour and centrifuged at $3000 \times g$ for 15 minutes. The plasma was separated and stored at $-70^{\circ} \mathrm{C}$.

\section{Induction of Experimentally Induced Dry Eye with Cholinergic Receptor Blockade}

Induction of experimentally induced dry eye (EIDE) was achieved by cholinergic receptor blockade as described by Dursun et al. ${ }^{24}$ Briefly, transdermal scopolamine patches were applied by cutting the patches into four pieces, wrapping them around the depilated midtail, and securing them with cellophane tape. Patches were reapplied on days $0,2,4$, and 6 .

\section{Corneal and Eyelid Histopathology}

Eyes and eyelids from WT and PLTP KO mice with and without EIDE were surgically excised, fixed in 10\% formalin, and embedded in paraffin. Sections $(6 \mu \mathrm{m})$ were prepared and stained with H\&E and PAS. Sections from three different eyes in each group were examined and photographed with a Nikon Eclipse TE2000-E (Nikon Corp., Tokyo, Japan) microscope equipped with a Nikon Digital Sight DS-5MC camera.

The corneal epithelial damage was assessed as described previously. ${ }^{25}$ In brief, the number of detaching apical cells was counted from a full microscope field-ofvision from three separate tissue sections, by two independent masked observers (N.L.S. and J.M.H.), using a $\times 20$ objective. Three mice were evaluated in each treatment group.

\section{Western Blot Analysis}

Plasma was collected as described earlier and tear fluid samples were collected in a glass microcapillary 
from the lateral canthus of WT and PLTP KO mice. Plasma and tears $(1 \mu \mathrm{L})$ were run on $12.5 \%$ SDS-polyacrylamide gel electrophoresis and electrically transferred to a nitrocellulose membrane ( $400 \mathrm{~mA}$ for $45 \mathrm{~min}$ utes) using $0.1 \mathrm{~mol} / \mathrm{L}$ Tris with $0.192 \mathrm{~mol} / \mathrm{L}$ glycine in $20 \%$ methanol as a transfer buffer. The membrane was blocked with milk powder (5\% wt/vol in Tris-buffered saline, $0.05 \%$ Tween, $\mathrm{pH} 7.5$, for 1 hour at room temperature). The membranes were subjected to electrochemiluminescence detection for PLTP using mAb59.

\section{Measurement of Aqueous Tear Production}

Tear production was measured before and 7 days after induction of EIDE. A Schirmer paper was cut in half, held with forceps, and applied to the ocular surface in the lateral canthus for 60 seconds. Wetting of the paper was measured in millimeters.

\section{Permeability to $\mathrm{CF}$}

CF ( $1 \mu \mathrm{L}$ of a $0.3 \%$ solution) was applied to the ocular surface. After 10 minutes the mice were sacrificed with high-dose carbon dioxide. Corneas without scleral rims were excised, rinsed twice with $200 \mu \mathrm{L}$ balanced salt solution, weighed, and placed in $100 \mu \mathrm{L}$ balanced salt solution. The solution containing the corneal tissue was protected from light and gently mixed for 90 minutes. The CF concentration in the incubation fluid was measured (excitation, $490 \mathrm{~nm}$; emission, $535 \mathrm{~nm}$ ) using a Wallac 1420 Victor2 Multilabel Counter (Beckman Coulter, Fullerton, CA). The results are reported as fluorescence units per milligram of corneal tissue.

\section{Occludin IHC}

Sections $(5 \mu \mathrm{m})$ of formalin-fixed, paraffin-embedded, whole eyes sections from WT, PLTP KO, and EIDE-induced WT and PLTP KO mice were mounted on chromium-gelatin-treated slides. The sections were first soaked in xylene to remove paraffin and then rehydrated in graded alcohol series (100\% to $70 \%)$. To recover antigenicity we pretreated the sections for 12 minutes at $37^{\circ} \mathrm{C}$ with pepsin $(0.5 \% \mathrm{wt} / \mathrm{vol})$ containing $0.1 \mathrm{~mol} / \mathrm{L} \mathrm{HCl}$. The sections were permeabilized and blocked with $0.1 \mathrm{~mol} / \mathrm{L}$ $\mathrm{Na}_{2} \mathrm{HPO}_{4}$ phosphate buffer containing $0.2 \%$ Triton X-100 and $10 \%$ normal goat serum for 60 minutes and labeled overnight in a moist chamber with polyclonal rabbit antioccludin primary antibody (dilution, 1:25) diluted in 0.1 $\mathrm{mol} / \mathrm{L}$ phosphate buffer containing $0.1 \%$ Triton $\mathrm{X}-100$ and $2.5 \%$ normal goat serum. Tissues without primary antibody served as negative controls. Sections were rinsed two times (30 minutes each) in phosphate buffer and labeled for 1 hour with Alexa 488-conjugated goat antirabbit immunoglobulin. The stained sections were rinsed three times (30 minutes each) in phosphate buffer and mounted with Aquamount (BDH Chemicals, Poole, UK) and coverslips were applied. The sections were examined under fluorescent illumination (excitation, 460$500 \mathrm{~nm}$; emission, $510-560 \mathrm{~nm}$ ) by a Nikon Eclipse TE2000-E microscope equipped with a Nikon Digital
Sight DS-5MC camera. The images were evaluated and quantitated further by Adobe Photoshop CS5 (San Jose, CA).

\section{Tear Fluid Osmolarity and Samples}

Tear fluid osmolarity $(\mathrm{mOsm} / \mathrm{L})$ in human subjects was measured with a Tearlab osmometer (Ocusense, Inc., San Diego, CA). Tear fluid samples ( 3 to $5 \mu \mathrm{L}$ ) subsequently were collected from the lower conjunctival sac using Blaubrand intramark 5- $\mu \mathrm{L}$ micropipets (Brand GMBH, Wertheim, Germany), causing minimal conjunctival irritation. The samples immediately were cooled and stored at $-18^{\circ} \mathrm{C}$ until analyzed.

\section{Preparation of Phosphatidylcholine Liposomes for PLTP Activity Measurement}

To prepare phosphatidylcholine liposomes, $10 \mu \mathrm{mol}$ of egg phosphatidylcholine (Sigma-Aldrich), $20 \mu \mathrm{L}$ (corresponding to $1 \mu \mathrm{Ci}$ ) of $\left[{ }^{14} \mathrm{C}\right]$ dipalmitoyl-phosphatidylcholine, and $100 \mathrm{nmol}$ of butylhydroxytoluene antioxidant (stock $1 \mathrm{nmol} / \mu \mathrm{L}$ in chloroform), were pipetted into glass tubes on ice. Organic solvent was evaporated under $\mathrm{N}_{2}$ until dry and the mixture was lyophilized for 30 minutes. Onto the dry lipid film $1 \mathrm{~mL}$ of PLTP buffer $(10 \mathrm{mmol} / \mathrm{L}$ Tris- $\mathrm{HCl}, 150 \mathrm{mmol} / \mathrm{L} \mathrm{NaCl}$, and $1 \mathrm{mmol} / \mathrm{L}$ EDTA, $\mathrm{pH}$ 7.4) was added and vortexed vigorously to solubilize lipid material. The sample was sonicated for $3 \times 5$ minutes in an ice bath. After each 5-minute sonication, the tubes rested 1 minute on ice, and then sonication was continued, avoiding foaming. The sonicated material was transferred into an Eppendorf (Hamburg, Germany) tube and centrifuged for 10 minutes at 15,000 rpm at room temperature to pellet particulate material and titanium residual released from the sonicator probe. The opalescent liposomes were transferred under $\mathrm{N}_{2}$ flow to a new 1-mL Eppendorf tube and kept at $+4^{\circ} \mathrm{C}$ wrapped in aluminum foil. By using this procedure, radioactivity counting of $15 \mu \mathrm{L}$ of this substrate produces about 15,000 cpm (16,300 dpm; counting efficiency, 92\%).

\section{PLTP-Facilitated Phospholipid Transfer Activity}

PLTP-facilitated phospholipid transfer activity was measured as follows: after solutions were pipetted to an Ep-

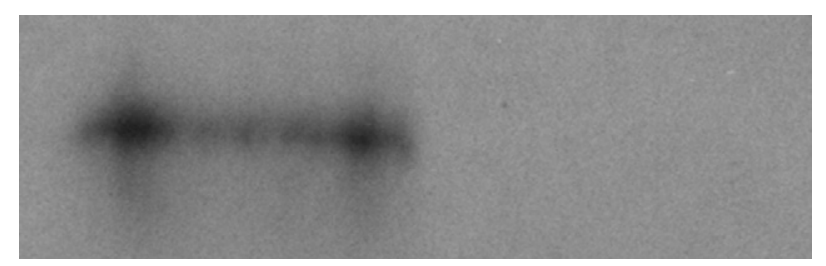

Figure 1. Western blot analysis of WT and PLTP KO mice plasma. Plasma collected from WT (left) and PLTP KO (right) mice were run on $12.5 \%$ SDS-polyacrylamide gel electrophoresis and electrically transferred to a nitrocellulose membrane. The membranes were subjected to electrochemiluminescence detection for PLTP using mAb59. 

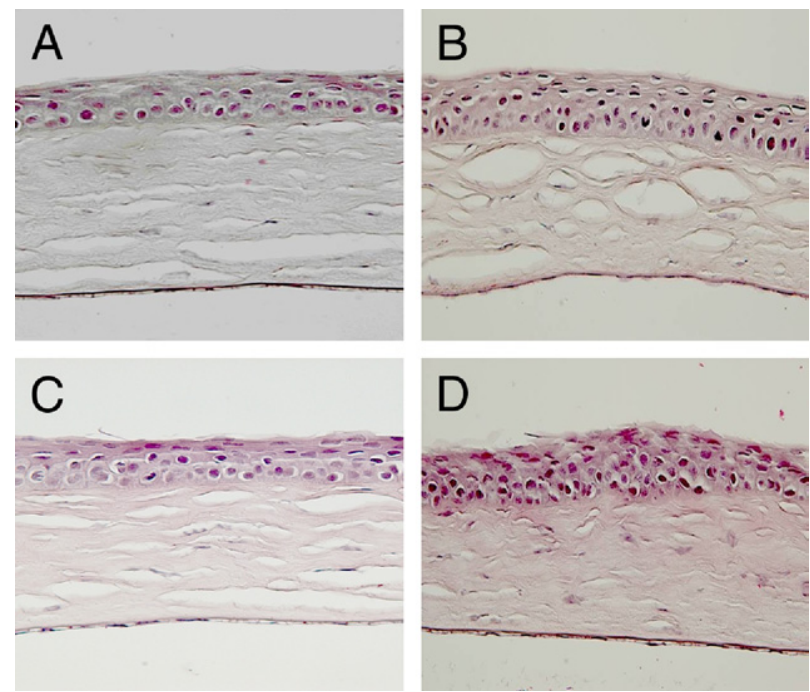

Figure 2. Histology of corneas of WT and PLTP KO mice. Histologic sections of paraffin-embedded corneas were stained with H\&E. A: Normal cornea of untreated C57BL/6 mouse. B: Cornea of untreated PLTP KO mouse with increased number of detaching apical cells. C: Cornea of normal WT mouse after 7 days of treatment with scopolamine patch. D: After 7 days of treatment with scopolamine patch PLTP KO showed corneal erosion and hyperkeratinization. Original magnification, $\times 40$.

pendorf tube: i) high-density lipoprotein ${ }_{3}$, (density range, 1.125 to $1.21 \mathrm{~g} / \mathrm{mL}$ ), free of PLTP activity, $250 \mu \mathrm{g}$ as protein; ii) Tris-buffer (10 mmol/L Tris-HCl, $154 \mathrm{mmol} / \mathrm{L}$ $\mathrm{NaCl}$, and $1 \mathrm{mmol} / \mathrm{L}$ EDTA, $\mathrm{pH}$ 7.4); iii) phosphatidylcholine liposomes, $15 \mu \mathrm{L}$; and iv) sample (1:10 diluted plasma or tear fluid, $10 \mu \mathrm{L})$. The final assay volume was $400 \mu \mathrm{L}$. The following tubes and controls were included: blank tube (buffer as a sample without PLTP), tube for total radioactivity per assay (total counts in $15 \mu \mathrm{L}$ ), and a control sample (frozen plasma or serum in $0.5-\mathrm{mL}$ aliquots stored at $-70^{\circ} \mathrm{C}$ ). Each of the earlier-described assay tubes was run in duplicate. The tubes were incubated at $37^{\circ} \mathrm{C}$ for 45 minutes in a water bath with light shaking. After incubation, the tubes were placed on ice and the reaction was stopped by adding $300 \mu \mathrm{L}$ of stopmix solution containing $7.2 \mathrm{~g} \mathrm{NaCl}$ and $10.5 \mathrm{~g} \mathrm{MnCl}_{2}$ in $224 \mathrm{~mL}$ of distilled $\mathrm{H}_{2} \mathrm{O}$ and $8 \mathrm{~mL}$ Heparin $(5000 \mathrm{IU} / \mathrm{mL}$;
Lövens, Ballerup, Denmark). After addition of the stopmix solution, the tubes were vortexed vigorously for 10 seconds, kept for 10 minutes at room temperature, and then centrifuged for 10 minutes at 15,000 rpm. After centrifugation, $500 \mu \mathrm{L}$ of supernatant was used for radioactivity counting. As a control with a normal PLTP activity (5000-7000 nmol/h/mL), fresh plasma or serum was collected and stored at $-70^{\circ} \mathrm{C}$ in $0.5-\mathrm{mL}$ aliquots. PLTP activity of this control was monitored in each assay series (in the beginning and at the end of the sample series). As a low PLTP activity control, serum or plasma with a low activity ( $2500 \mathrm{nmol} / \mathrm{mL} / \mathrm{h})$ was used. This control was stored under the same conditions as the normal control.

\section{Statistics}

The Student's $t$-test or the Mann-Whitney $U$-test were used where appropriate for between-group statistical comparisons.

\section{Results}

\section{PLTP Is Present in Plasma and in Tear Fluid in WT Mice}

Blood samples were drawn from WT and PLTP KO mice. High immunoreactivity for PLTP was seen in the plasma of WT mice but was totally absent in the plasma of PLTP $\mathrm{KO}$ mice (Figure 1). Pooled tear fluid samples of 3 eyes derived from both normal and PLTP KO groups then were analyzed using Western blot with anti-PLTP mAb59 antibody. Normal C57BL/6 mice showed strong immunoreactivity at the apparent molecular weight of approximately $80 \mathrm{kDa}$, at the predicted molecular weight of PLTP. In the tear fluid of PLTP KO mice no immunoreactive PLTP was detected (data not shown).

\section{Aqueous Tear Production}

The pharmacologic cholinergic receptor blockade with transdermal scopolamine patches leads to a significant reduction of aqueous tear production. ${ }^{24,25}$ PLTP KO and
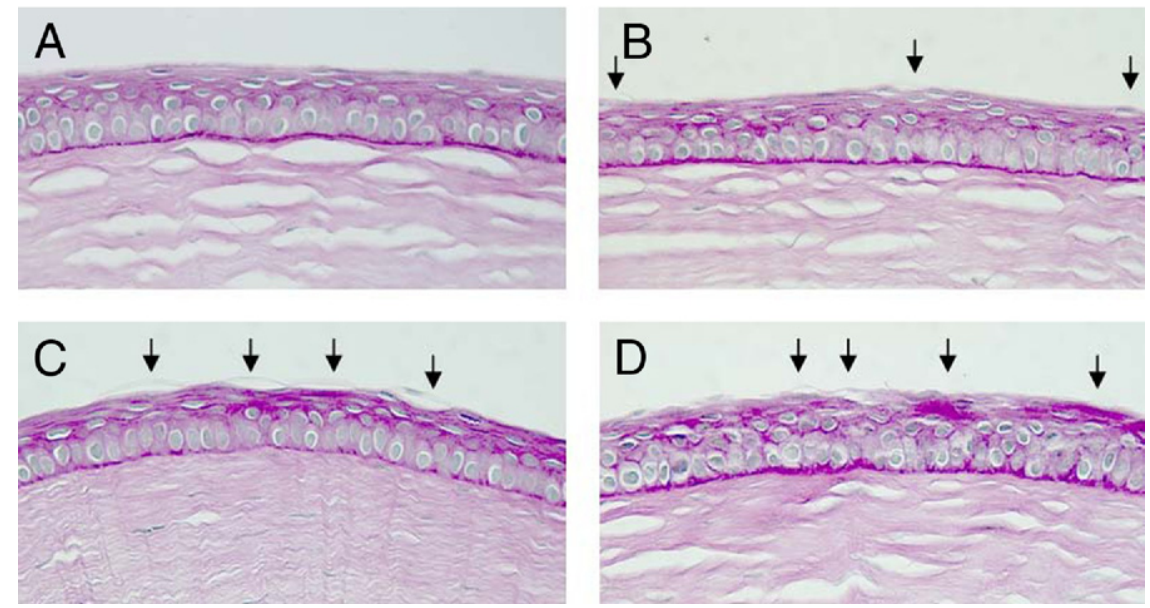

Figure 3. PAS staining of WT and PLTP KO mouse corneas. A: Normal cornea of WT C57BL/ 6 mouse. B: Cornea staining of untreated PLTP KO mouse with visible detaching superficial corneal epithelial cells. C: Cornea of normal WT mouse after 7 days of EIDE D: After 7 days of EIDE, PLTP KO showed significant damage to the corneal epithelium. Arrows indicate detaching apical cells. Original magnification, $\times 40$. 
WT mice had similar tear production before induction of EIDE ( $2.1 \pm 0.2$ and $2.2 \pm 0.2 \mathrm{~mm}$, respectively). After 7 days of EIDE the tear productions were decreased significantly in WT and PLTP KO mice $(0.2 \pm 0.1 \mathrm{~mm}$ for both). No statistical difference in tear production in these two groups was detected after EIDE.

\section{Corneal Histology}

Mouse corneas were stained with H\&E and PAS. WT mouse corneas showed no evidence of ocular surface disease (Figures 2A and $3 \mathrm{~A}$ ). In contrast, in PLTP KO mouse corneas, detaching apical cells were observed significantly more frequently (Figures $2 \mathrm{~B}$ and $3 \mathrm{~B} ; P=$ 0.015). The number of these detaching apical cells was even higher in both EIDE-induced WT (Figures 2C and $3 \mathrm{C}$ ) and PLTP KO (Figures $2 \mathrm{D}$ and $3 \mathrm{D}$ ) mouse corneas (both $P<0.001$ ).

During the study period a total of 253 PLTP KO mice were housed in our laboratory. In this group, six (2.4\%) spontaneous perforations were observed; in the same period of time WT C57BL/6 mice $(n=631)$ had no corneal perforations. We analyzed one of the perforated eyes by staining whole eye with H\&E (Figure 4). The perforation was observed paracentrally and it had selfsealed by outpunching of the iris to the perforated ulcus. Stromal damage was evident and infiltration of lymphocytes to the ulcus area was seen. Adjacent epithelia was disorganized and thickened.

\section{Corneal Epithelial Permeability Is Increased Significantly in PLTP KO Mice}

Increased corneal epithelial permeability to CF is a characteristic finding in dry eye. Corneal epithelial permeability to CF (molecular weight, $750 \mathrm{Da}$ ) was assessed in WT, PLTP KO, and EIDE WT and PLTP KO mice. Compared with WT mice, permeability to CF was increased significantly in PLTP KO mice and also in both EIDE mice groups (Figure 5).

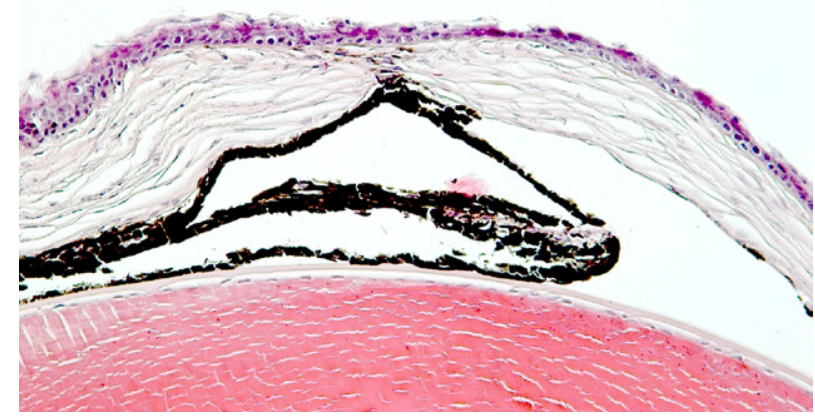

Figure 4. H\&E staining of a spontaneously perforated PLTP KO mouse cornea. Original magnification, $\times 40$.

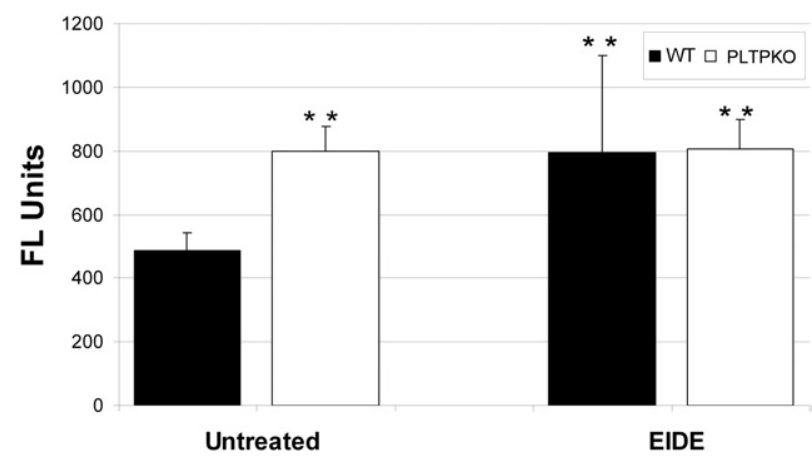

Figure 5. Corneal permeability to $750 \mathrm{Da} C F$ in untreated and after 7 days of EIDE in WT (black bars) and PLTP KO (white bars) mice. ${ }^{* * *} P<0.01$ compared with WT mice. The results are reported as fluorescence units/mg corneal tissue. FL units, units of fluorescein emission at $535 \mathrm{~nm}$.

\section{PLTP KO Mice Have Decreased Expression of the Tight Junction Protein Occludin}

The normal cornea barrier function is maintained by tight junctions in the differentiated apical corneal epithelial cells. Increased occludin cleavage (ie, diminished occludin expression) has been reported in dry eye. ${ }^{25}$ Corneal endothelium showed strong immunoreactivity against polyclonal occludin antibody and this immunoreactivity was used to normalize occludin expression in the epithelium, that is, epithelial immunoreactivity was compared with endothelial immunoreactivity, which was considered to be constant in all studied mice groups. In WT mice occludin protein expression was seen in the endothelium as well as in the epithelium, but not in the corneal stroma (not shown). The

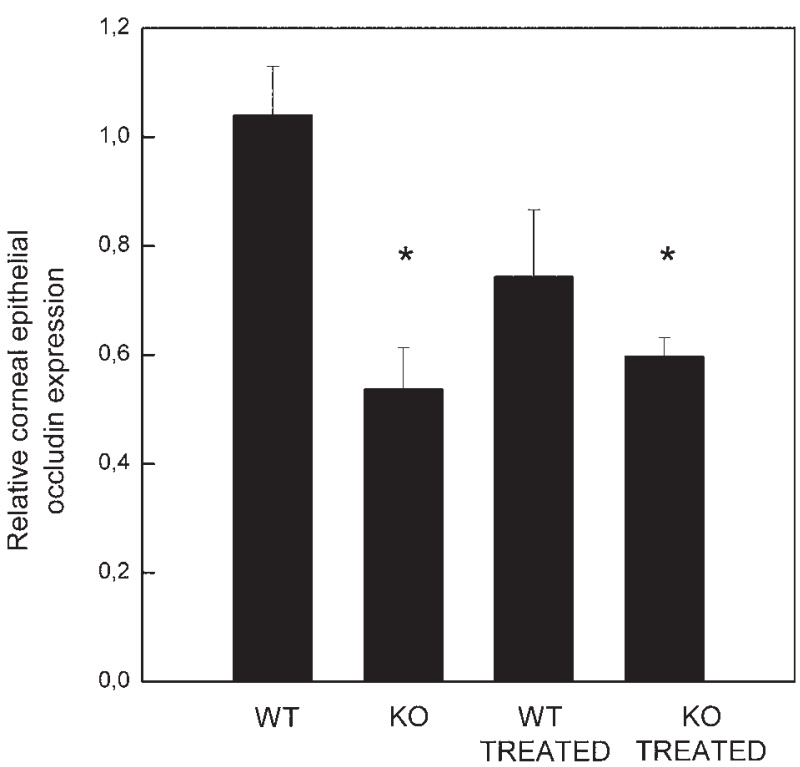

Figure 6. Corneal epithelial occludin expression in WT and PLTP KO mice. Compared with normal C57BL/6 mice PLTP KO mice showed significant reduction in occludin expression. Scopolamine blockade also reduces occludin expressions in PLTP KO mice and to a lesser extent in C57BL/6 mice. The measured epithelial anti-occludin fluorescence values were standardized by dividing epithelial fluorescence count with endothelial fluorescence values. ${ }^{*} P<0.05$ compared with untreated WT C57BL $/ 6$ mice. 


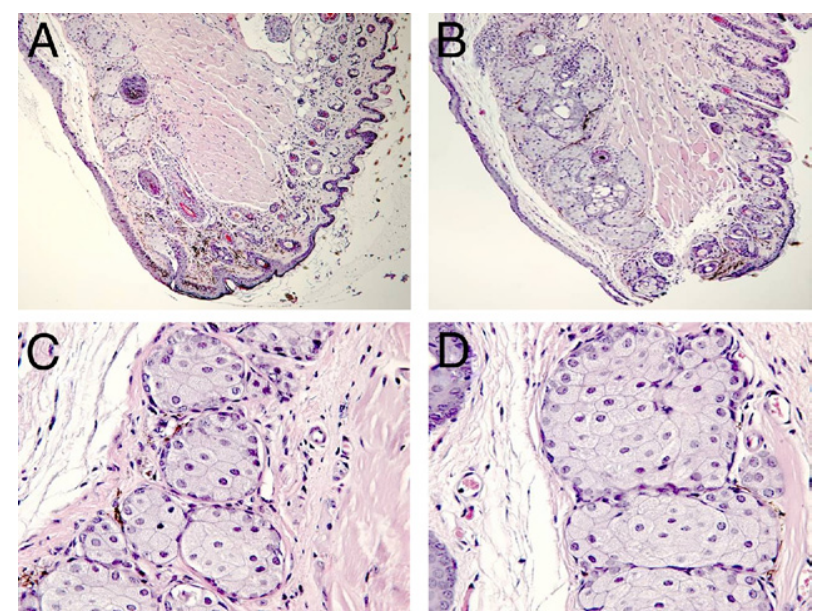

Figure 7. Histology of meibomian glands of WT C57BL/6 and PLTP KO mice. Tarsal sections of WT and PLTP KO C57BL/6 mice were prepared from eyelids and used for histologic examination (H\&E staining). The mice were 8 -week-old females. A: Structure of normal mouse lid (original magnification, $\times 10$ ). B: Structure of PLTP KO mouse lid (original magnification, $\times 10$ ). Structure of meibomian glands of normal (C) and PLTP KO (D) mice (original magnification, $\times 40)$.

expression pattern for occludin in PLTP KO mice was significantly different: endothelium showed bright immunofluorescence but epithelial expression was reduced significantly (not shown). Both EIDE mice showed decreased epithelial occludin protein expression (not shown). Quantitation of epithelial occludin protein expression confirmed these findings and showed a significantly decreased expression of occludin in PLTP KO mice as well as in EIDE PLTP KO mice compared with WT mice $(P<0.05$; Figure 6$)$. Although epithelial occludin expression was lower in EIDE WT mice compared with WT mice, this result was not significant $(P=0.11)$.

\section{PLTP KO Mice Show Normal Histology of Eyelids}

In several dry eye KO models, such as ACAT-1 null (ACAT-1-/-) mice, the dry eye symptoms arise from the atrophy of the palpebral glands. ${ }^{26}$ To verify that the observed dry eye induction was not caused by atrophy of the meibomian glands we examined the histology of WT and PLTP KO mice eyelids. The histologic analysis of PLTP KO mice eyelids was normal and the histology of meibomian glands was similar to those in WT mice (Figure 7).

\section{Tear Hyperosmolarity Increases PLTP Activity in Human DES Patients}

Tear fluid hyperosmolarity is considered a universal finding in DES patients. ${ }^{3}$ Accordingly, we measured the tear fluid osmolarity for 7 DES patients and 4 healthy controls (Figure 8). Dry eye patients showed significantly higher tear fluid osmolarity compared with healthy controls (302 to 309 versus 320 to $336 \mathrm{mOsm} / \mathrm{L} ; P<0.001$ ). After the osmolarity measurements a tear fluid sample of approx- imately $5 \mu \mathrm{L}$ was collected from the lower conjunctival sac and PLTP activity was assessed from these samples. In DES patients PLTP activity was found to be significantly higher $(8873 \pm 2118 \mu \mathrm{mol} / \mathrm{mL} / \mathrm{h}$; range, $6276-$ $12,545 \mu \mathrm{mol} / \mathrm{mL} / \mathrm{h}$ ) compared with healthy controls (4180 \pm $1490 \mu \mathrm{mol} / \mathrm{mL} / \mathrm{h}$; range, 2492-6220 $\mu \mathrm{mol} / \mathrm{mL} / \mathrm{h})(P=$ 0.003).

\section{Discussion}

We report here that mice deficient in PLTP show characteristic DES findings. The PLTP KO mice showed morphologic changes in corneal epithelium, increased corneal permeability to CF, and cleavage of corneal epithelial occludin. The tear fluid production in PLTP KO mice was constant and comparable with that shown in wild-type littermates. Also, the eyelid and meibomian gland morphologies were normal. During our experimental follow-up time $2.4 \%$ of PLTP KO mice suffered spontaneous perforation of an eye, whereas the wild-type animals grown under the same conditions had no eye problems. Finally, our preliminary studies showed increased tear fluid PLTP activity in human DES patients compared with healthy controls, suggesting a protective role for PLTP in human beings also.

Dry eye symptoms detectable in PLTP-deficient mice were compared with the dry eye mouse model described by Dursun et al, ${ }^{24}$ in which tear fluid production is attenuated by the cholinergic blockade with scopolamine. This approach was chosen because it does not cause anatomic changes in lacrimal or palpebral structures. Compared with the cholinergic blockade, the PLTP KO mice showed similar corneal changes, increased corneal permeability, and cleavage of epithelial occludin. Furthermore, the cholinergic blockade reduced tear production as described earlier. ${ }^{24,25}$ We also treated the PLTP KO mice with scopolamine to see whether the effects are additive. PLTP KO with EIDE did not induce further corneal permeability or occludin cleavage. This could be explained by the two models separately causing maximal permeability to CF with the concentrations used. The activation of matrix metalloproteases, especially matrix metalloprotease-9, which primarily are responsible for occludin cleavage in corneal epithelium, ${ }^{27}$ seems to be

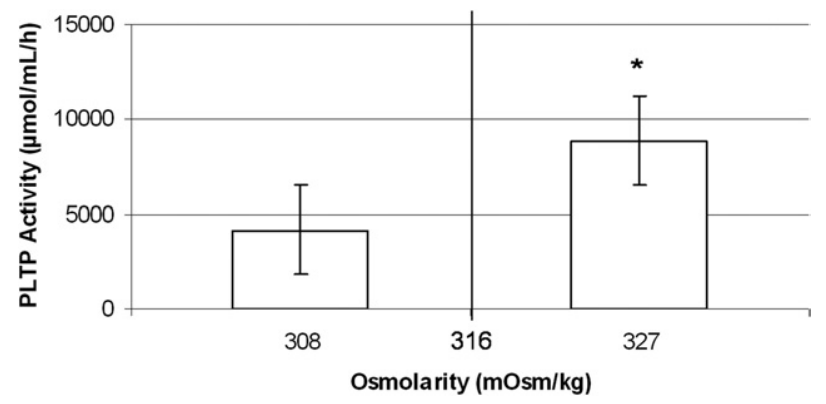

Figure 8. Assessment of tear fluid PLTP activity in human DES patients and healthy controls. DES patients showed significantly increased tear fluid osmolarity $(P<0.001)$ with a concomitant increases in tear fluid PLTP activity $\left({ }^{*} P=0.003\right)$ 
involved with the same outcome both in PLTP KO animals and with EIDE treatment.

Several animal models that mimic human dry eye have been introduced and they have been important tools for investigating the multiple factors that have been implicated in the pathogenesis of DES. Yet, several of the present DES models resemble tear deficiency or Sjögren syndrome-like autoimmune disease because they diminish aqueous tear production via mechanical, ${ }^{28}$ autoimmune, ${ }^{29,30}$ or chemical ${ }^{24}$ effect on the lacrimal gland. Because the tear lipid film imbalance and the evaporative DES are common diseases of the eye especially among elderly citizens, a model that carefully mimics this condition is of utmost importance. Mechanical cauterization of meibomian gland orifices presented by Gilbard et $\mathrm{al}^{31}$ and other lid surgery techniques definitely affect tear lipid film composition, but the normal appearance of palpebral aperture is easily hampered. Different mouse models of meibomian gland dysfunction (including aplasia, hypoplasia, and atrophy) have been generated through mutant and transgenic techniques. ${ }^{32}$ These models definitely have their advantages; however, such a total absence of tear lipids is rare in human DES. Also, the tear lipid film composition seems to differ from direct meibomian secretion. ${ }^{33}$ Few animal models introduced for blepharitis ${ }^{34}$ show reduction in tear fluid lipid production associated with dry eye symptoms, but also in these models the normal anatomic appearance of either lid or eye surface typically is altered. In addition, the blepharitis itself induces ocular surface irritation and alters the immunologic profile of the ocular surface, which is an important factor in the development of DES.

We have reported previously that PLTP is found in normal human tear fluid in at least twofold higher concentration from that observed in plasma. ${ }^{16}$ Both apolipoproteins $A-I$ and $E$ that are capable of interacting with PLTP in plasma ${ }^{35}$ are absent in tear fluid, and therefore these protein-protein interactions are lacking. ${ }^{21}$ Nevertheless, PLTP is active in tear fluid. ${ }^{21}$ Very recently we showed that PLTP interacts with mucin in tear fluid, which can be a functionally important complex. ${ }^{17}$ Based on the current data we suggest that a possible explanation for the presence of PLTP in the tear fluid may be a scavenging property of PLTP: the lipid contamination from the anterior lipid layer of the tear film is directed to the ocular surface. Here, PLTP can remove the harmful overload of lipids and other lipophilic substances and transfer these to the lacrimal drainage system. It needs to be emphasized that PLTP can maximally bind and transfer 43 and 13 moles of phosphatidylcholine and cholesterol, respectively, per mole of PLTP, ${ }^{36}$ allowing for a very efficient lipid transfer activity. This mode of action is very similar to the one described for human tear lipocalin. ${ }^{14}$ In line with these findings human DES patients show significantly increased levels of PLTP activity in tears, suggesting an induction of PLTP activity in hyperosmolar conditions. However, it needs to be emphasized that at present we have no evidence that the absence of PLTP in the tear fluid per se causes DES. It also may be envisioned that PLTP may possess anti-inflammatory or other protective functions in the tear fluid. This is in line with the proposed pleiotropic effects of PLTP in plasma, ${ }^{37}$ as well as with the very high lipid binding and transfer potential of PLTP. ${ }^{36}$ We believe that the mouse PLTP KO model serves as a relevant model of human DES. The specific mechanism of PLTP in lipid transfer processes in tear, detailed lipid composition of tear fluid, and possible alterations in PLTP activity in DES patients will be important targets to investigate in more detail to define the exact role of PLTP in DES.

\section{Acknowledgment}

We thank Leena Kainulainen for experienced animal care.

\section{References}

1. Goto E, Endo K, Suzuki A, Fujikura Y, Matsumoto Y, Tsubota K: Tear evaporation dynamics in normal subjects and subjects with obstructive meibomian gland dysfunction. Invest Ophthalmol Vis Sci 2003, 44:533-539

2. Gilbard JP, Farris RL: Tear osmolarity and ocular surface disease in keratoconjunctivitis sicca. Arch Ophthalmol 1979, 97:1642-1646

3. Tomlinson A, Khanal S, Ramaesh K, Diaper C, McFadyen A: Tear film osmolarity: determination of a referent for dry eye diagnosis. Invest Ophthalmol Vis Sci 2006, 47:4309-4315

4. Pflugfelder SC, Jones D, Ji Z, Afonso A, Monroy D: Altered cytokine balance in the tear fluid and conjunctiva of patients with Sjogren's syndrome keratoconjunctivitis sicca. Curr Eye Res 1999, 19:201-211

5. Bron AJ, Tiffany JM, Gouveia SM, Yokoi N, Voon LW: Functional aspects of the tear film lipid layer. Exp Eye Res 2004, 78:347-360

6. Pakarinen M, Tervo T, Tarkkanen A: Tarsorraphy in the treatment of persistent corneal lesions. Acta Ophthalmol Suppl 1987, 182:69-73

7. Holly FJ: Formation and rupture of the tear film. Exp Eye Res 1973, 15:515-525

8. McCulley JP, Shine W: A compositional based model for the tear film lipid layer. Trans Am Ophthalmol Soc 1997, 95:79-88

9. Butovich IA: The Meibomian puzzle: combining pieces together. Prog Retin Eye Res 2009, 28:483-498

10. Chen HB, Yamabayashi S, Ou B, Tanaka Y, Ohno S, Tsukahara S: Structure and composition of rat precorneal tear film. A study by an in vivo cryofixation. Invest Ophthalmol Vis Sci 1997, 38:381-387

11. Greiner JV, Glonek T, Korb DR, Leahy CD: Meibomian gland phospholipids. Curr Eye Res 1996, 15:371-375

12. McCulley JP, Shine WE: Meibomian secretions in chronic blepharitis. Adv Exp Med Biol 1998, 438:319-326

13. Steinman RM, Mellman IS, Muller WA, Cohn ZA: Endocytosis and the recycling of plasma membrane. J Cell Biol 1983, 96:1-27

14. Glasgow BJ, Marshall G, Gasymov OK, Abduragimov AR, Yusifov TN, Knobler CM: Tear lipocalins: potential lipid scavengers for the corneal surface. Invest Ophthalmol Vis Sci 1999, 40:3100-3107

15. Saaren-Seppala H, Jauhiainen M, Tervo TM, Redl B, Kinnunen PK, Holopainen JM: Interaction of purified tear lipocalin with lipid membranes. Invest Ophthalmol Vis Sci 2005, 46:3649-3656

16. Jauhiainen M, Setala NL, Ehnholm C, Metso J, Tervo TM, Eriksson O, Holopainen JM: Phospholipid transfer protein is present in human tear fluid. Biochemistry 2005, 44:8111-8116

17. Setala NL, Holopainen JM, Metso J, Yohannes G, Hiidenhovi J, Andersson LC, Eriksson O, Robciuc A, Jauhiainen M: Interaction of phospholipid transfer protein with human tear fluid mucins. J Lipid Res 2010, 51:3126-3134

18. Huuskonen J, Ehnholm C: Phospholipid transfer protein in lipid metabolism. Curr Opin Lipidol 2000, 11:285-289

19. Tall AR, Krumholz S, Olivecrona T, Deckelbaum RJ: Plasma phospholipid transfer protein enhances transfer and exchange of phospholipids between very low density lipoproteins and high density lipoproteins during lipolysis. J Lipid Res 1985, 26:842-851

20. Jiang XC, D'Armiento J, Mallampalli RK, Mar J, Yan SF, Lin M: Expression of plasma phospholipid transfer protein mRNA in normal 
and emphysematous lungs and regulation by hypoxia. J Biol Chem 1998, 273:15714-15718

21. Setala NL, Holopainen JM, Metso J, Wiedmer SK, Yohannes G, Kinnunen PK, Ehnholm C, Jauhiainen M: Interfacial and lipid transfer properties of human phospholipid transfer protein: implications for the transfer mechanism of phospholipids. Biochemistry 2007, 46: 1312-1319

22. Siggins S, Jauhiainen M, Olkkonen VM, Tenhunen J, Ehnholm C: PLTP secreted by HepG2 cells resembles the high-activity PLTP form in human plasma. J Lipid Res 2003, 44:1698-1704

23. Jiang XC, Bruce $C$, Mar J, Lin M, Ji Y, Francone OL, Tall AR: Targeted mutation of plasma phospholipid transfer protein gene markedly reduces high-density lipoprotein levels. J Clin Invest 1999, 103:907-914

24. Dursun D, Wang M, Monroy D, Li DQ, Lokeshwar BL, Stern ME, Pflugfelder SC: A mouse model of keratoconjunctivitis sicca. Invest Ophthalmol Vis Sci 2002, 43:632-638

25. Pflugfelder SC, Farley W, Luo L, Chen LZ, De Paiva CS, Olmos LC, Li $D Q$, Fini ME: Matrix metalloproteinase-9 knockout confers resistance to corneal epithelial barrier disruption in experimental dry eye. Am J Pathol 2005, 166:61-71

26. Yagyu H, Kitamine T, Osuga J, Tozawa R, Chen Z, Kaji Y, Oka T, Perrey S, Tamura Y, Ohashi K, Okazaki H, Yahagi N, Shionoiri F, lizuka Y, Harada K, Shimano H, Yamashita H, Gotoda T, Yamada N, Ishibashi S: Absence of ACAT-1 attenuates atherosclerosis but causes dry eye and cutaneous xanthomatosis in mice with congenital hyperlipidemia. J Biol Chem 2000, 275:21324-21330

27. Smith VA, Rishmawi H, Hussein H, Easty DL: Tear film MMP accumulation and corneal disease. $\mathrm{Br} J$ Ophthalmol 2001, 85:147-153

28. Maitchouk DY, Beuerman RW, Ohta T, Stern M, Varnell RJ: Tear production after unilateral removal of the main lacrimal gland in squirrel monkeys. Arch Ophthalmol 2000, 118:246-252
29. Humphreys-Beher MG, Hu Y, Nakagawa Y, Wang PL, Purushotham KR: Utilization of the non-obese diabetic (NOD) mouse as an animal model for the study of secondary Sjogren's syndrome. Adv Exp Med Biol 1994, 350:631-636

30. Zhu Z, Stevenson D, Schechter JE, Mircheff AK, Atkinson R, Trousdale MD: Lacrimal histopathology and ocular surface disease in a rabbit model of autoimmune dacryoadenitis. Cornea 2003, 22:25-32

31. Gilbard JP, Rossi SR, Heyda KG: Tear film and ocular surface changes after closure of the meibomian gland orifices in the rabbit. Ophthalmology 1989, 96:1180-1186

32. Barabino S, Dana MR: Animal models of dry eye: a critical assessment of opportunities and limitations. Invest Ophthalmol Vis Sci 2004, 45:1641-1646

33. Butovich IA: On the lipid composition of human meibum and tears: comparative analysis of nonpolar lipids. Invest Ophthalmol Vis Sci 2008, 49:3779-3789

34. Chan CC, Gery I, Kohn LD, Nussenblatt RB, Mozes E, Singer DS: Periocular inflammation in mice with experimental systemic lupus erythematosus. A new experimental blepharitis and its modulation. J Immunol 1995, 154:4830-4835

35. Karkkainen M, Oka T, Olkkonen VM, Metso J, Hattori H, Jauhiainen M, Ehnholm C: Isolation and partial characterization of the inactive and active forms of human plasma phospholipid transfer protein (PLTP). J Biol Chem 2002, 277:15413-15418

36. Nishida HI, Nishida T: Phospholipid transfer protein mediates transfer of not only phosphatidylcholine but also cholesterol from phosphatidylcholine-cholesterol vesicles to high density lipoproteins. J Biol Chem 1997, 272:6959-6964

37. Albers JJ, Cheung MC: Emerging roles for phospholipid transfer protein in lipid and lipoprotein metabolism. Curr Opin Lipidol 2004 , 15:255-260 